\title{
Factors related to transmission of and infection with Schistosoma mansoni in a village in the South-eastern Region of Brazil
}

\author{
Martin Johannes Enk ${ }^{1 /+}$, Anna Carolina Lustosa Lima ${ }^{2}$, Heliton da Silva Barros ${ }^{3}$, \\ Cristiano Lara Massara ${ }^{4}$, Paulo Marcos Zech Coelho', Virginia Torres Schall ${ }^{3}$
}

${ }^{1}$ Laboratório de Esquistossomose ${ }^{2}$ Departamento de Apoio Científico, Unidade de Bioestatística ${ }^{3}$ Laboratório de Educação em Saúde

${ }^{4}$ Laboratório de Helmintologia e Malacologia Médica, Instituto de Pesquisas René Rachou-Fiocruz, Belo Horizonte, MG, Brazil

In this transversal study, factors related to infection with and transmission of Schistosoma mansoni were explored. Based on stool examinations of two Kato-Katz smears of a single sample, the prevalences of schistosomiasis and geohelminths were established. In a multivariable analysis, sets of demographic, socio-economic and water contact pattern variables were tested for strength of relation with infection. Males presented a 3.39-times higher risk for infection than females. The age groups between 10-19 years and 20-30 years showed risks of infection 7.1and 7.5-times higher, respectively, than the control age group between 0-10 years. Individuals practicing leisure activities had a 1.96-times higher risk than those without these activities. The malacological survey identified snails of the species Biomphalaria glabrata, Biomphalaria straminea and Biomphalaria tenagophila. Two exemplars of B. glabrata $(0.53 \%)$ proved positive for $\mathrm{S}$. mansoni. The socio-economic improvements observed in the locality suggest a protective and preventive effect towards infection with schistosomiasis, which requires further investigation with a longitudinal and more detailed study design. Considering our findings, a proposal for an integrated control program should be based on two pillars: one horizontal, which involves social empowerment and health education, and another more vertical, which delivers treatment and infrastructure improvements.

Key words: schistosomiasis - Schistosoma mansoni - socio-economic factors - risk factors - area of low transmission - Brazil

There is much scientific evidence that socio-demographic variables and contact with unsafe water are associated with infection with schistosomiasis. Studies in different settings have been carried out describing vulnerable parts of the population, such as school children, types of behaviour related to a higher risk of acquiring the infection, as is the case with household, occupational and leisure activities, or involving socio-economical status and its correlation to the disease (Lima e Costa 1983, Guimarães et al. 1985, Cairncross et al. 1996, da Silva et al. 1997, Barbosa \& Barbosa 1998, Moza et al. 1998, Watts et al. 1998, Bethony et al. 2001, 2004, Massara et al. 2004, Gazzinelli et al. 2006). Studies carried out in Africa investigating infections with Schistosoma haematobium present similar associations, demonstrating the importance of studies involving snail hosts, water contacts and micro-spatial distribution for an integrated epidemiological approach (Stothard et al. 2002).

The data presented in this paper are part of a broader project with a primary focus on diagnostic and control strategies for Schistosoma mansoni in an endemic area (Enk et al. 2008). This study intended to investigate some aspects of the association between infections with $S$. man-

\footnotetext{
Financial support: FAPEMIG, CNPq, SUS

+ Corresponding author: marenk@cpqrr.fiocruz.br

Received 12 December 2008

Accepted 8 October 2009
}

soni and general demographic, socio-economic and water contact pattern variables in the village of Chonim de Cima and to give an overall view about the transmission and maintenance of the disease in this area. Therefore, a malacological survey was carried out and an evaluation of safe water supply and sanitation issues was also part of this study. It also tried to gather knowledge on specific local features of water contact that determine schistosomiasis infection, providing support to elaborate control strategies involving local communities (Barbosa et al. 1996). Seeking such conditional characteristics allows investigators to realise local people's behaviour, enabling an association between the disease and activities that may result in an increased risk for infection, in order to propose specific preventive strategies (Laurrell \& Gil 1975).

\section{PATIENTS, MATERIALS AND METHODS}

Study area and population - The village of Chonim de Cima is situated in the county of Governador Valadares in the north-east of the state of Minas Gerais (MG), Brazil. The district of Chonim de Cima covers an area of $175 \mathrm{~km}^{2}$ in the north of the county. The area is characterised by multiple water sources, including brooks, swamps and small lakes that are used for professional and leisure activities of the local population.

The brook, before it enters the village, is used as the main water source for drinking and domestic needs of the population. For this purpose, the water is pumped to a water treatment station, which is run by the municipalityowned Water and Sewerage Company of Governador Valadares. The treated and chlorinated water is stored in water tanks and finally delivered through a pipe system to the consumers in all households of the village. As the brook 
crosses the village, it serves as the principal recipient for sewage of in numerous individual drainages of households nearby. At the brook's exit from the village, the canalisation system delivers untreated sewage into its water.

The economy of the village is based on cattle breeding for meat and milk production, subsidiary agriculture, small businesses and local trade. The only school of the district is situated in the centre of the village and receives pupils from the rural and urban areas. The school enrolment rate is above $90 \%$, representing the Brazilian average. Basic medical support is provided by a team of the Community Health Assistance Program (PACS), consisting of five health technicians, based in a little health facility. A medical doctor, together with a fully trained nurse, attends patients of the district each Monday and Wednesday. In the cases of specific medical examinations, treatment or hospitalisation, patients are taken to Governador Valadares, which is $30 \mathrm{~km}$ from the village and can be reached by driving $10 \mathrm{~km}$ on a dirt road and $20 \mathrm{~km}$ on an asphalt street.

This study area was selected because it is situated in an area at the low range of medium prevalence for schistosomiasis, where the community never received previous chemotherapy treatment through the National Schistosomiasis Control Program (SCP) and the village's population was adequate in size for the study purpose and characterised by a low rate of migration.

During a census carried out in cooperation with the local health authorities (PACS), 1,448 residents living in 404 households were registered. Non-permanent residents (183 individuals) and 204 residents of the rural area of the district were excluded from this study, resulting in a total population of 1,061 participants investigated.

Parasitological survey - A cross-sectional parasitological survey was carried out in all households. A single stool sample of each household member was examined according to the Kato-Katz thick smear technique using two slides for each sample (Katz et al. 1972). The slides were prepared in a field laboratory in Chonim de Cima by a well trained technician of the regional health agency. After that, two experienced laboratory technicians of the Laboratory of Schistosomiasis performed the microscopic examination in the René Rachou Research Institute (CPqRR). Approximately 10\% of all examined slides were subjected to a control system for diagnostic efficacy. The results for soil-transmitted helminths (STHs) were expressed qualitatively and those for $S$. mansoni were expressed quantitatively to obtain the number of eggs per gram (epg). For each individual, the arithmetic mean epg of faeces based on the two samples was calculated. For analysis on group and population levels, the intensity of infection was calculated as the geometric mean of the egg counts of positive individuals.

Treatment - All participants positive for schistosomiasis were treated with praziquantel according to the recommendation of the Brazilian Ministry of Health (adults, 50 $\mathrm{mg} / \mathrm{kg}$ in a single oral dose, children $\leq 15$ years old, 60 $\mathrm{mg} / \mathrm{kg}$ in a single oral dose). Those positive for STHs were treated with albendazole (adults and children, $400 \mathrm{mg}$ in a single oral dose) in the local health facility.
Malacological survey - A senior technician from the regional centre of disease control (Regional Section of Decentralized Health Assistance), trained by the CPqRR and with large experience in snail collection, carried out the survey in the presence of one member of the research team. Snails were collected from the brooks crossing the village and swamps, little ponds, irrigation ponds and fish reservoirs within the urban area. Additionally, two sites used by the local population for leisure activities were examined for the presence of molluscs. The collection process was performed with perforated metal dippers fixed on a wooden stick and wooden tweezers (Thiengo 1995).

After capture, the molluscs were packed in boxes especially designed for transport and taken to the laboratory. Those alive were measured and examined in small plastic flasks with de-chlorinated water under artificial light in order to verify the presence of $S$. mansoni cercariae. Five snails from each collection site were identified based on comparative morphology of the reproductive organs and shell as described by Deslandes (1951) and Paraense (1975) and submitted to molecular analysis according to Vidigal et al. (2000). The other snails were submitted to smashing between glass plates for verification of the presence of sporocysts and cercariae.

Demographic, socio-economic, water contact variables and data collection - Different sets of variables, which have shown association with transmission and infection in other study areas, were chosen to evaluate their relation to the disease in our setting (Bethony et al. 2004, Massara et al. 2004, Gazzinelli et al. 2006). In order to investigate these different sets of variables, a questionnaire based on a model developed by Firmo (1994) during research activities in the region of Gorduras, Belo Horizonte, MG and adapted to the local conditions of this study area was used.

The following four sets of variables were investigated in this study: (i) a demographic set, including name, age, gender and family's origin, (ii) a socio-economic set, consisting of information about water supply, presence of electrical energy, household possessions (car, bicycle, television set, radio, refrigerator), regime of ownership (proper or rent), total household income (less or more than 2 minimum wages), education (none, 1st grade, 2 nd grade and more than 2nd grade) and occupation (children and school children, manual and rural worker, employed in service sector, housewife, housekeeper, retired person and pensioner and unemployed), (iii) a set of information about sanitation devices, including sewage disposal (canalisation, septic pit, rudimentary pit and direct disposal into the brook) and infrastructure of toilet (presence of toilet and type of floor) and (iv) a set about water contact patterns categorised into leisure activities (swimming and fishing), horticultural activities, fetching water, occupational exposure to untreated water and crossing natural water collections, which means water contact with the bare feet when crossing brooks or swamps.

A team of four trained interviewers, all from the CPqRR, was in charge to carry out the survey. Prior to the survey, they were trained to conduct the interviews by using personal digital assistants. They visited all house- 
holds. After signing a consent form for each resident of the household, a representative, in most cases the head of the household, was interviewed about general conditions and possessions of the residence. Individual data, including water contact pattern, were obtained by questioning each member of the household. In the case of children with less than seven years of age, this information was gathered by asking the household representative who answered the questionnaire about the residence.

Data analysis - The Chi-square test was applied to compare proportions between groups. The odds ratio was used to determine the strength of association of results from stool examinations between groups of the population. The relationship between infection with $S$. mansoni and demographic, socio-economic and water contact variables was explored with univariate logistic regression. Considering all variables revealing a $\mathrm{p}$ value $<0.20$ and sequentially removing the variable with the highest $p$ value until all variables showed a $p$ value $<0.005$ was the adapted procedure of the multivariate logistic regression to develop the final model. All tests were carried out with a $95 \%$ level of confidence. The software package Minitab 14.0 was used to carry out these calculations.

Ethical considerations - All participants were informed about the purpose of this study, the possible risks and inconveniences. The study protocol was received and approved by the Ethical Review Board of the CPqRR (04/2005). The study was carried out between 2004-2006.

\section{RESULTS}

Population - The study population of 1,061 individuals consisted of 597 (56.3\%) females and 464 (43.7\%) males living in 351 residences. There was a significant difference between the proportion of female and male populations (Chi-square test: $16.672, \mathrm{p}$ value $=0.000$ ) . The age of this population ranged from 0-96 years, revealing a mean age of 27 years (23-30 years, CI 95\%) and a median age of 32 years (30.6-33.4 years, CI 95\%). The extreme age groups, less than 10 years and more than 60 years, represented $19.2 \%$ and $17.2 \%$, respectively, of the entire population. More than $40 \%$ of the population was younger than 20 years. The detailed figures of the population correlating age and gender are shown in Table I.

A total of 336 households, representing $95.7 \%$ of the population, had access to electrical energy and 299 households, representing $86.1 \%$ of the population, received treated water. Regarding the issue of sewage disposal, 188 households, representing $53.3 \%$ of the population, were connected to the public sewage system, 99 households, or $29.2 \%$ of the population, used some sort of pit and the rest of the households, or $17.5 \%$ of the population, drained their sewage directly into the brook.

Parasitological survey - The parasitological survey of all 1,061 participants revealed a total of 119 individuals infected with $S$. mansoni, indicating a prevalence of $11.2 \%$. Males, with a proportion of $18.1 \%$ schistosomiasis positive, showed a 3.1-times higher infection rate than females, with a proportion of $5.9 \%$. The overall geometric mean egg count was 61.1 (63.6 for females and 60.1 for males). As shown in Fig. 1, the highest infection rates occurred in the age group from 10-30 years and as shown in Table II, the highest epg were found in the age group of children up to 10 years.

The results of prevalence of STHs were equal to or greater than $2 \%$, except for hookworm infections, which reached a level of $10.4 \%$ (Table III). A proportion of $1.8 \%$ of the population revealed co-infection with two or more STHs and 2\% showed co-infection with schistosomiasis and one or more STH.

Malacological survey - Out of the 30 collection sites in the urban area, 491 snails of the genus Biomphalaria were found at $22(73.3 \%)$ locations. At both sites used for recreation and leisure activities outside of the village, 27 snails were captured. Of 391 live molluscs, $235(60.1 \%)$ were identified as Biomphalaria straminea, 152 (38.9\%) as Biomphalaria glabrata and four (1\%) as Biomphalaria tenagophila. Remarkably, each snail species seemed to prefer a specific habitat. All specimens of $B$. straminea were found in brooks, those of B. glabrata only in little

TABLE I

The population of Chonim de Cima, Governador Valadares, Minas Gerais, Brazil, by age and gender

\begin{tabular}{lcccccccc}
\hline & \multicolumn{2}{c}{ Females } & & \multicolumn{3}{c}{ Males } & & \multicolumn{3}{c}{ Total } \\
\cline { 2 - 3 } \cline { 8 - 9 } Age group & $\mathrm{n}$ & $\%$ & & $\mathrm{n}$ & $\%$ & & $\mathrm{n}$ & $\%$ \\
\hline $0-10$ & 102 & 17.1 & & 102 & 22 & & 204 & 19.2 \\
$10-20$ & 142 & 23.8 & & 116 & 25 & & 258 & 24.3 \\
$20-30$ & 59 & 9.9 & & 36 & 7.8 & & 95 & 9 \\
$30-40$ & 68 & 11.4 & & 39 & 8.4 & & 107 & 10.1 \\
$40-50$ & 66 & 11.1 & & 47 & 10.1 & & 113 & 10.7 \\
$50-60$ & 64 & 10.7 & & 38 & 8.2 & & 102 & 9.6 \\
$>60$ & 96 & 16.1 & & 86 & 18.5 & & 182 & 17.2 \\
\hline Total & 597 & 56.3 & & 464 & 43.7 & & 1,061 & 100 \\
\hline
\end{tabular}




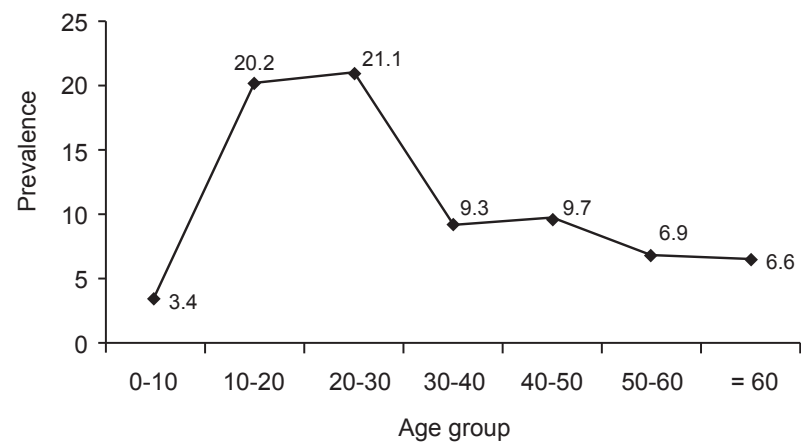

Fig. 1: relation between age group and proportion of schistosomiasis positives among the population of Chonim de Cima, Governador Valadares, Minas Gerais, Brazil $(\mathrm{n}=1,061)$.

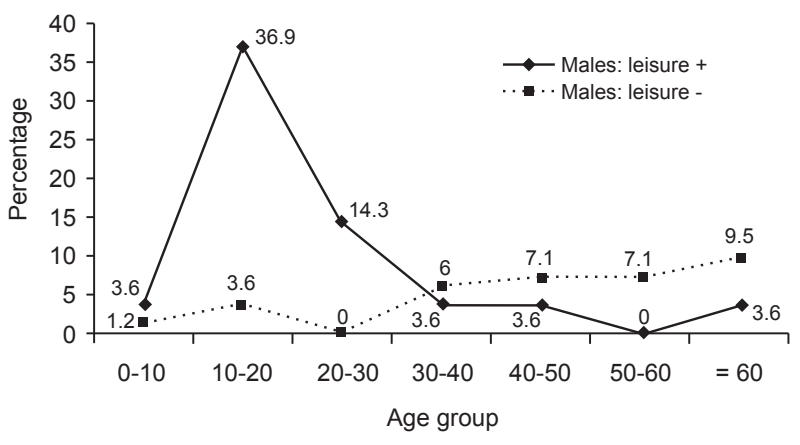

Fig. 2: relation between age groups, schistosomiasis positive males practicing leisure activities (males: leisure + ) and schistosomiasis positive males not practicing leisure activities (males: leisure -) among the population of Chonim de Cima, Governador Valadares, Minas Gerais, Brazil.

TABLE II

Number of schistosomiasis positives and negatives, prevalence and egg count per gram (epg) in relation to gender and age group among the population of Chonim de Cima, Governador Valadares, Minas Gerais, Brazil $(\mathrm{n}=1,061)$

\begin{tabular}{lccccc}
\hline & \multicolumn{5}{c}{ Results } \\
\cline { 2 - 6 } Variable & $\begin{array}{c}\text { Negatives } \\
\mathrm{n}\end{array}$ & $\begin{array}{c}\text { Positives } \\
\mathrm{n}\end{array}$ & Total & $\%$ & epg \\
\hline Gender & & & & \\
Male & 380 & 84 & 464 & 18.1 & 60.1 \\
Female & 562 & 35 & 597 & 5.9 & 63.6 \\
Age group & & & & \\
$0-10$ & 197 & 7 & 204 & 3.4 & 160.1 \\
$10-20$ & 206 & 52 & 258 & 20.2 & 65.1 \\
$20-30$ & 75 & 20 & 95 & 21.1 & 59.5 \\
$30-40$ & 97 & 10 & 107 & 9.3 & 72.2 \\
$40-50$ & 102 & 7 & 113 & 9.7 & 80.3 \\
$50-60$ & 95 & 12 & 182 & 6.9 & 20 \\
$\geq 60$ & 170 & 119 & 1,061 & 11.2 & 35.7 \\
\hline Total & 942 & & & 6.6 \\
\hline
\end{tabular}

ponds and water reservoirs and all B. tenagophila snails were captured in a single pond, which was used for fishing. A total of $376(96.2 \%)$ live molluscs were examined for infection with $S$. mansoni and two snails, or $0.53 \%$, proved positive, both for the species B. glabrata. Considering only $B$. glabrata snails in the evaluation, the infection rate increased to $1.6 \%$ among this species.

Demographic, socio-economic and water contact variables - A univariate logistic regression was conducted in order to identify a significant relationship between infection with $S$. mansoni and potential risk factors represented by demographic, socio-economic and water contact variables.

Among the demographic variables considered, a significant relation was found between infection and gen- der, as well as age group. Males showed a 3.39-times $(95 \% \mathrm{CI}=2.2-5.3)$ higher risk for infection than females. The most notable results were found in the age groups between 10-19 years and 20-30 years, in which the risk of infection was $7.1(95 \% \mathrm{CI}=3.2-16.0)$ and 7.5-times higher $(95 \% \mathrm{CI}=3.0-18.5)$ than in the control, with an age between $0-10$ years. The family's origin was also associated with infection, revealing that families with origin outside of the study area were at lower risk.

The socio-economic variables related to infection with schistosomiasis are shown in Table IV. The rest of this set of variables, including water supply, presence of electrical energy, household possessions, regime of ownership and household income, revealed no statistically significant relationship with infection. 
TABLE III

Prevalence of soil transmitted helminths among the population of Chonim de Cima, Governador Valadares, Minas Gerais, Brazil $(\mathrm{n}=1,061)$

\begin{tabular}{|c|c|c|c|}
\hline Type of soil transmitted helminth & $\begin{array}{c}\text { Positives } \\
\mathrm{n}\end{array}$ & $\begin{array}{c}\text { Negatives } \\
\mathrm{n}\end{array}$ & $\%$ \\
\hline Ascaris lumbricoides & 17 & 1,044 & 1.6 \\
\hline Hookworm & 110 & 951 & 10.4 \\
\hline Enterobius vermicularis & 21 & 1,040 & 2 \\
\hline Trichuris trichiura & 0 & 1,061 & 0 \\
\hline Taenia sp. & 19 & 1,042 & 1.8 \\
\hline Hymenolepis nana & 7 & 1,054 & 0.7 \\
\hline
\end{tabular}

TABLE IV

Risk and 95\% confidence intervals (CI) for schistosomiasis infection of individuals (n) according to socio-economic variables among the population of Chonim de Cima, Governador Valadares, Minas Gerais, Brazil $(\mathrm{n}=1,061)$

\begin{tabular}{|c|c|c|c|c|c|}
\hline Variable & $\mathrm{n}$ & $\mathrm{p}$ value & Risk & \multicolumn{2}{|c|}{$95 \% \mathrm{CI}$} \\
\hline & & 0.002 & & & \\
\hline Non & 270 & - & 1.0 & - & - \\
\hline 1st grade & 644 & 0.003 & 2.4 & 1.3 & 4.2 \\
\hline 2nd grade & 131 & 0.000 & 3.8 & 1.9 & 7.6 \\
\hline More than 2nd grade & 16 & 0.907 & 1.1 & 0.1 & 9.2 \\
\hline Occupation & & 0.000 & & & \\
\hline Children and schoolchildren & 376 & - & 1.0 & - & - \\
\hline Manual and rural worker & 140 & 0.000 & 3.9 & 2.3 & 6.5 \\
\hline Service sector & 94 & 0.576 & 1.2 & 0.6 & 2.6 \\
\hline Housewife, housekeeper, retired and handicapped & 371 & 0.139 & 0.7 & 0.4 & 1.1 \\
\hline Unemployed & 79 & 0.004 & 2.6 & 1.4 & 5.1 \\
\hline
\end{tabular}

The variables connected with the household's sanitation revealed no relationship with infection in the case of sewage disposal $(\mathrm{p}$ value $=0.25)$ and presence of toilet ( $\mathrm{p}$ value $=0.42$ ). The infrastructure of the toilet, evaluated by the type of floor, presented a significant association with the disease. The risk decreased according to the increase of the infrastructure's quality, showing values of $0.4(95 \% \mathrm{CI}=0.2-0.8)$ for ceramic floors and $0.5(95 \% \mathrm{CI}=0.3-1.0)$ for concrete floors compared to floors without improvement.

The evaluation of the water contact pattern of the population in relation to infection is shown in Table V. The strongest association was found for the variable of leisure activities, showing a 3.5-fold increased risk (95\% CI $=2.4-5.2$ ) for those individuals practicing these activities.

Table VI shows the final multivariable model for schistosomiasis infection. According to the results of this model, males were at higher risk than females and the age groups between 10-30 years showed the highest values of association with the infection. Members of the community who practiced leisure activities involv- ing water contact with natural water sources were also at higher risk than those without these activities. Further analysis of the schistosomiasis-positive male population in relation to age group and leisure activities showed that $51.2 \%$ of this population was between $10-30$ years old and practiced leisure activities. Fig. 2 provides more detailed information about these distributions.

\section{DISCUSSION}

Bio-ecological data obtained in the present study reveal that the district of Chonim de Cima provides adequate environmental conditions for the vector reproduction and parasite survival expressed by schistosomiasis-positive individuals, as well as by infected snails. Considering the fact that the population never received treatment through the SCP raises the question why the infection rate among the residents of this village is not higher. Based on data from the socio-economic survey, the most probable answer is that measures related to social improvement, especially a safe water supply $(86.1 \%$ of the population), indicate a protective and preventive 
TABLE V

Risk and 95\% confidence intervals (CI) for schistosomiasis infection according to water contact variables among the population of Chonim de Cima, Governador Valadares, Minas Gerais, Brazil $(\mathrm{n}=1,061)$

\begin{tabular}{|c|c|c|c|c|c|}
\hline Variable & $\mathrm{n}$ & $\mathrm{p}$ value & Risk & \multicolumn{2}{|c|}{$95 \% \mathrm{CI}$} \\
\hline No & 718 & - & 1.0 & - & - \\
\hline Yes & 343 & - & 3.5 & 2.4 & 5.2 \\
\hline Watering garden & & 0.999 & & & \\
\hline No & 1,051 & - & 1.0 & - & - \\
\hline Yes & 10 & - & 0 & 0 & 0 \\
\hline Fetching water & & 0.695 & & & \\
\hline No & 1,028 & - & 1.0 & - & - \\
\hline Yes & 33 & - & 0.8 & 0.2 & 2.6 \\
\hline Occupational exposure to untreated water & & 0.158 & & & \\
\hline No & 1,023 & - & 1.0 & - & - \\
\hline Yes & 38 & - & 1.8 & 0.8 & 4.3 \\
\hline Crossing natural water sources & & 0.016 & & & \\
\hline No & 937 & - & 1.0 & - & - \\
\hline Yes & 124 & - & 1.9 & 1.1 & 3.1 \\
\hline
\end{tabular}

effect on infection with schistosomiasis. This assumption is confirmed by two studies recently carried out in other endemic areas in MG (Castro 2009, Vasconcelos et al. 2009). In our study, a difference in the distribution of infection according to gender was found. Females were at lower risk because their pattern of water contact involves, due to their more domestic activities, mainly safe water sources. No relation of infection with schistosomiasis and the occupation category, which includes this section of the population (housewife, housekeeper, handicapped and retired persons), could be found.

Furthermore, the occupation category of manual and rural worker, mainly males, showed a strong relationship to infection, due to contact with unsafe water. On the other hand, the effect of the protective factor - safe water - is hampered by the lack of another important social achievement: the insufficient sanitation system. According to our data, $70.8 \%$ of all households deliver untreated sewage into the main brook of the village, significantly facilitating the maintenance of the transmission of schistosomiasis in the area. The natural water resources, which are used for leisure purposes, become contaminated and an important source of infection in this way. As described in the final multivariable model, leisure activities represent an important risk factor to acquire infection with schistosomiasis. Putting this finding into the broader context of an integrated schistosomiasis control program, the importance of social improvements, which include the majority of the population, becomes evident. The current strategy, which focuses mainly on the treatment of the positives, has a paramount role on the individual level without any doubt. However, on the community level, the option of treatment without concurrent social improvements, especially in the water and sanitation sector, seems to be less effective, efficient and in the long term, less sustainable, because re-infection occurs after treatment as long as the environment remains contaminated with the parasite (Coura-Filho et al. 1996).

This study also intended to identify subsets of the population that are more vulnerable to infection with schistosomiasis. According to the final model, males in the age group between 10-30 years practicing leisure activities related to contact with unsafe water show the highest accumulative risk of infection. Although vulnerability for infection depends on environmental, demographic and socio-economic factors specific for each endemic area, our data follow, in some aspects a pattern that was found in other study areas. In particular, the age group of 10-30 years represents such a subset of the population, which seems to be common (Lima e Costa 1983, Gazzinelli et al. 2006).

This information may be useful for the planning of more differentiated control programs that consider an approach involving target groups in areas of low or medium prevalence. Considering our findings, a proposal for an integrated control program may be based on two pillars: one, horizontal, which involves social empowerment and health education and another one more vertical, which delivers treatment and infrastructural improvements.

In conclusion, this study shows that the factors related to the transmission of and infection with schistosomiasis cannot be understood only as a consequence of a variety of demographical, socio-economical and biological variables, which differ among study areas, but must also be seen in a framework in which different and complex biological and social systems interact and influence each other in a permanent search for homeostasis. 


\section{TABLE VI}

Multivariable model of the association between demographic, socio-economic and water contact variables and infection with schistosomiasis among the population of Chonim de Cima, Governador Valadares, Minas Gerais, Brazil $(n=1,061)$

\begin{tabular}{|c|c|c|c|c|c|}
\hline Variable & $\mathrm{n}$ & $\mathrm{p}$ value & Risk & \multicolumn{2}{|c|}{$95 \% \mathrm{CI}$} \\
\hline Female & 597 & - & 1.00 & - & - \\
\hline Male & 464 & - & 3.39 & 2.17 & 5.28 \\
\hline Age group & & 0.000 & & & \\
\hline $0-10$ & 236 & - & 1.00 & - & - \\
\hline $10-20$ & 235 & 0.000 & 6.50 & 3.05 & 13.86 \\
\hline $20-30$ & 96 & 0.000 & 7.54 & 3.20 & 17.76 \\
\hline $30-40$ & 110 & 0.020 & 3.08 & 1.20 & 7.96 \\
\hline $40-50$ & 110 & 0.013 & 3.26 & 1.29 & 8.24 \\
\hline $50-60$ & 104 & 0.210 & 1.99 & 0.68 & 5.87 \\
\hline$\geq 60$ & 170 & 0.073 & 2.29 & 0.93 & 5.67 \\
\hline Leisure activity (swimming and fishing) & & 0.003 & & & \\
\hline No & 718 & - & 1.00 & - & - \\
\hline Yes & 343 & - & 1.96 & - & 3.06 \\
\hline Total & 1,061 & - & - & - & - \\
\hline
\end{tabular}

Finally, it is worth mentioning here that data of another study, which analysed in depth the proportion of schistosomiasis positives among a representative sample of the same population, revealed a significant variation (Enk et al. 2008). According to the methodology applied in this study, the prevalence showed levels of $11.4 \%$ for two Kato-Katz slides of a single stool sample. In another study, the prevalence found was $35.4 \%$ for 10 Kato-Katz slides of three stool samples combined with stool examinations carried out according to the formol ether centrifugation technique (Blagg et al. 1955).

This evidence indicates that prevalence is roughly underestimated, because approximately two-thirds of the positives are not detected if the routine sampling effort is applied. This finding strongly suggests that the association of the above evaluated variables with schistosomiasis has to be seen with caution whenever one or two slides of a single stool sample are used to define prevalence. That also means that in our case, a comparison of the demographic and socio-economic data with the higher and lower prevalence values might bring a deeper insight into this issue. Nevertheless, this evidence shows that the real situation of infection with schistosomiasis in areas considered of low and medium prevalence requires more attention and a more sophisticated approach in order to obtain reliable information.

\section{ACKNOWLEDGEMENTS}

To Aureo Almeida de Oliveira, senior technician of the Laboratory of Schistosomiasis, for his valuable contribution in realizing the field work and examining the stool samples, and for the excellent cooperation of the technical team of the Secretary of Health in the state of Minas Gerais, Section Governador Valadares.

\section{REFERENCES}

Barbosa CS, Barbosa FS 1998. Padrão epidemiológico da esquistossomose em comunidade de pequenos produtores rurais de Pernambuco, Brasil. Cad Saude Publica 14: 129-137.

Barbosa CS, da Silva CB, Barbosa FS 1996. Schistosomiasis: reproduction and expansion of the endemia to the state of Pernambuco in Brazil. Rev Saude Publica 30: 609-616.

Bethony J, Williams JT, Brooker S, Gazzinelli A, Gazzinelli MF, LoVerde PT, Corrêa-Oliveira R, Kloos H 2004. Exposure to Schistosoma mansoni infection in a rural area in Brazil. Part III. Household aggregation of water contact behaviour. Trop Med Int Health 9: 381-389.

Bethony J, Williams JT, Kloos H, Blangero J, Alves-Fraga L, Buck G, Michalek A, Williams-Blangero S, Loverde PT, Corrêa-Oliveira R, Gazzinelli A 2001. Exposure to Schistosoma mansoni infection in a rural area in Brazil. II. Household risk factors. Trop Med Int Health 6: 136-145.

Blagg W, Schloegel EL, Mansour NS, Khalaf GI 1955. A new concentration technic for the demonstration of protozoa and helminth eggs in feces. Am J Trop Med Hyg 4: 23-28.

Cairncross S, Blumenthal U, Kolsky P, Moraes L, Tayeh A 1996. The public and domestic domains in the transmission of disease. Trop Med Int Health 1: 27-34.

Castro AKS 2009. Avaliação clínica-epidemiológica da esquistossomose mansoni em Comercinho, MG (1981-2005), MSc Thesis, Santa Casa de Belo Horizonte, Belo Horizonte, 138 pp.

Coura-Filho P, Rocha RS, Lamartine SS, Farah MW, de Resende DF, Costa JO, Katz N 1996. Control of schistosomiasis mansoni in Ravena (Sabará, state of Minas Gerais, Brazil) through water supply and quadrennial treatments. Mem Inst Oswaldo Cruz 91: 659-664.

da Silva AA, Cutrim RN, de Britto e Alves MT, Coimbra LC, Tonial SR, Borges DP 1997. Water-contact patterns and risk factors for Schistosoma mansoni infection in a rural village of Northeast Brazil. Rev Inst Med Trop Sao Paulo 39: 91-96. 
Deslandes N 1951. Técnica de dissecção e exame de planorbídeos. Rev Serv Espec Saude Publ 4: 371-382.

Enk MJ, Lima AC, Drummond SC, Schall VT, Coelho PM 2008. The effect of the number of stool samples on the observed prevalence and the infection intensity with Schistosoma mansoni among a population in an area of low transmission. Acta Trop 108: 222-228.

Firmo JOA 1994. Avaliação clínico-epidemiológica da esquistossomose mansoni em uma área de periferia de Belo Horizonte, Minas Gerais, MSc Thesis, Universidade Federal de Minas Gerais, 135 pp.

Gazzinelli A, Velasquez-Melendez G, Crawford SB, LoVerde PT, CorreaOliveira R, Kloos H 2006. Socioeconomic determinants of schistosomiasis in a poor rural area in Brazil. Acta Trop 99: 260-271.

Guimarães MD, Lima e Costa MF, Lima LB, Moreira MA 1985. Clinical-epidemiological study of schistosomiasis mansoni in schoolchildren of Ilha, Arcos District, Minas Gerais, Brazil, 1983. Rev Saude Publica 19: 8-17.

Katz N, Chaves A, Pellegrino J 1972. A simple device for quantitative stool thick-smear technique schistosomiasis mansoni. Rev Inst Med Trop Sao Paulo 14: 397-400.

Laurrell AC, Gil JB 1975. Morbilidad, ambiente y organización social. Un modelo teorico para analises de la enfermedad en el medio rural. Salud Publica Mex 17: 471-478.

Lima e Costa MFF 1983. Estudos clínico-epidemiológicos da esquistossomose mansoni em Comercinho, Minas Gerais (19741981), PhD Thesis, Universidade Federal de Minas Gerais, Belo Horizonte, $207 \mathrm{pp}$.
Massara CL, Peixoto SV, Barros HS, Enk MJ, Carvalho OS, Schall V 2004. Factors associated with schistosomiasis mansoni in a population from the municipality of Jaboticatubas, state of Minas Gerais, Brazil. Mem Inst Oswaldo Cruz 99 (Suppl. I): 127-134.

Moza PG, Pieri OS, Barbosa CS, Rey L 1998. Fatores sócio-demográficos e comportamentais relacionados à esquistossomose em uma agrovila da zona canavieira de Pernambuco, Brasil. Cad Saude Publica 14: 107-115.

Paraense WL 1975. Estado atual da sistemática de planorbídeos brasileiros. Arq Mus Nac 55: 105-128.

Stothard JR, Mgeni AF, Khamis S, Seto E, Ramsan M, Rollinson D 2002. Urinary schistosomiasis in schoolchildren on Zanzibar Island (Unguja), Tanzania: a parasitological survey supplemented with questionnaires. Trans R Soc Trop Med Hyg 96: $507-514$

Thiengo S 1995. Técnicas malacológicas. In FS Barbosa, Tópicos em malacologia médica, Editora Fiocruz, Rio de Janeiro, p. 225-260.

Vasconcelos CH, Cardoso PC, Quirino WC, Massara CL, Amaral GL, Cordeiro R, Carvalho OS 2009. Evaluation of schistosomiasis mansoni control measures in Sabará, Minas Gerais state, Brazil, 1980-2007. Cad Saude Publica 25: 997-1006.

Vidigal TH, Caldeira RL, Simpson AJ, Carvalho OS 2000. Further studies on the molecular systematics of Biomphalaria snails from Brazil. Mem Inst Oswaldo Cruz 95: 57-66.

Watts S, Khallaayoune K, Bensefia R, Laamrani H, Gryseels B 1998. The study of human behavior and schistosomiasis transmission in an irrigated area in Morocco. Soc Sci Med 46: 755-765. 